\title{
Explaining state-level differences in brain cancer mortality in the United States by population ancestries: a spatial approach
}

\author{
Ari Voutilainen ${ }^{* 1}$, Paula R. Sherwood ${ }^{2}$ \\ ${ }^{1}$ Department of Nursing Science, University of Eastern Finland, Kuopio, Finland \\ ${ }^{2}$ Department of Acute and Tertiary Care, School of Nursing, University of Pittsburgh, Pittsburgh, PA, USA
}

Received: June 1, 2015

DOI: $10.5430 /$ jer.v1n $1 \mathrm{p} 12$

\author{
Accepted: July 6, 2015 \\ Online Published: July 15, 2015 \\ URL: http://dx.doi.org/10.5430/jer.v1n1p12
}

\begin{abstract}
To some extent, the spatial differences in brain cancer mortality rate appear to arise from the difference in the mortality between ethnic groups. In the United States (US), for example, brain cancer mortality rate is higher among White Non-Hispanic than other groups. The US brain cancer mortality data (age-adjusted and pooled over 2007-2011) were gathered from the State Cancer Profiles web site. The brain cancer mortality rates were associated with the geographic distribution of different ancestral and ethnic groups at the state-level by applying three different statistical analyses to find out the most evident spatial patterns. The geographic distribution of the brain cancer mortality was related to the proportion of foreign-born Black and White in the US population so that the mortality rate was high in the states were the proportion of foreign-born was low and vice versa. The only ancestries which increased the mortality among White Non-Hispanic in the US population were from a relatively restricted area in Europe including Germany, Czech Republic, the Netherlands, Luxemburg, Belgium, and the Nordic countries except for Iceland. This study gave reasons for the discussion about the possible existence of population-level genetic susceptibilities to the brain cancer and/or higher risk of mortality. Brain cancer mortality in general as well as the present results apply mainly to gliomas.
\end{abstract}

Key Words: Ancestry, Brain cancer, Mortality, Spatial epidemiology, The United States

\section{INTRODUCTION}

Mortality rates for primary malignant tumors of the brain and other parts of the central nervous system (termed as brain cancer henceforth) differ between areas worldwide being highest in certain parts of Eastern and Southern Europe and lowest in Sub-Saharan Africa. ${ }^{[1,2]}$ In the case of Sub-Saharan Africa, the low mortality, and incidence, rates may partly be results of unreliable data. ${ }^{[1]}$ Among high-income countries providing reliable data brain cancer mortality and incidence rates are lowest in Japan. ${ }^{[1]}$ Mechanisms explaining spatial differences in mortality following diagnosis are not wellknown, partly due to variations in the quality and amount of data gathered across countries. ${ }^{[2]}$ Ethnicity is one of the variables that has been linked to some of the differences in mortality. ${ }^{[3]}$ In the United States (US), brain cancer mortality rates are higher among White Non-Hispanic persons compared to other racial and ethnic groups and, consequently, the areas where the proportion of White Non-Hispanic persons is highest are characterized by the highest mortality rate. ${ }^{[4]}$ Ethnicity, however, does not completely explain the spa-

\footnotetext{
${ }^{*}$ Correspondence: Ari Voutilainen; Email: ari.voutilainen@uef.fi; Address: Department of Nursing Science, University of Eastern Finland, Yliopistonranta 1C, P.O. Box 1627, 70211 Kuopio, Finland.
} 
tial variation in brain cancer mortality, as the mortality rate among White Non-Hispanic also differs between areas. ${ }^{[4]}$ In general, the survival rate for brain cancer depends largely upon the tumor type, of which glioblastoma is the most fatal type, and patient age has an inverse relationship with younger persons having lower mortality rates. ${ }^{[5]}$ Potential causes of different types of brain cancer have been studied for decades, but very few determinants have been recognized, ionizing radiation as a risk factor of glioma being perhaps the most evident one. ${ }^{[6,7]}$ In addition to ionizing radiation, glioma risk may be inversely associated with diabetes and allergy/atopy. ${ }^{[8,9]}$ Current explanations for brain cancer are increasingly linked to the genome. ${ }^{[8,10]}$

The purpose of the present registry-based study was to investigate associations between brain cancer mortality rates and ethnicity of the US population by applying a multimethodological spatial approach. Briefly, spatial thinking in epidemiology refers to the study of geographic variation in disease-related variables, such as incidence, prevalence, and mortality. ${ }^{[1]}$ Spatial epidemiology aims to combine spatial patterns of the target variable in question with those obeyed by the proposed explanatory factors. Similar spatial patterns are implicitly assumed to represent a relationship between the variables but, naturally, the relationship needs to be verified as accurately as possible prior to the interpretation of results. The development of (open and closed-source) statistical environments has in its part made it possible for the spatial approach to become more common. ${ }^{[12]}$

The US was chosen as the target area due to high quality of the brain cancer data ${ }^{[2]}$ and because brain cancer in general is so rare, approximately four deaths per 100,000 people globally, that a very large population is required to receive enough cases to carry out reliable analyses. The US population is composed of groups with different ethnic origins, which enabled the association of mortality data with numerous ancestries. The US provides an excellent study area for registry-based spatial research. It is large and distributed into states and counties and most registered variables are linked namely to these administrative regions.

\section{MethodS}

\subsection{Data collection}

Brain cancer data were gathered from the State Cancer Profiles web site, ${ }^{[4]}$ which is a collaboration between the National Cancer Institute and the Centers for Disease Control and Prevention. Average annual (2007-2011) brain cancer mortality (deaths per 100000 population) was used as the dependent variable in the analyses. The mortality is calculated by the National Cancer Institute using the SEER*Stat statistical software and age-adjusted to the 2000 US stan-

Published by Sciedu Press dard population. The State Cancer Profiles also provides data concerning "universal" risk factors of most cancer types, such as obesity, fruit and vegetable consumption, exercise, and smoking, but there is no clear consensus on their effects on brain cancer (gliomas) incidence, prevalence, and mortality. ${ }^{[6]}$ The State Cancer Profiles are based on the most recent data that have completed the national quality assurance processes. ${ }^{[4]}$ In this study, mortality was chosen as the target variable because it combines effects of risk factors (incidence) and coping with the disease (lethality). In general, the mortality and incidence rates from brain cancer show similar worldwide patterns. ${ }^{[6]}$ Data regarding ethnicity (as in 2010) were obtained from the American FactFinder web site that provides data from annual surveys and censuses conducted by the US Census Bureau. ${ }^{[13]}$ The data fulfill the Census Bureau's Statistical Quality Standards. ${ }^{[13]}$ A state was the statistical unit in all analyses.

\subsection{Statistical analyses}

The procedure known as Principal Coordinates of Neighbor Matrices $(\mathrm{PCNM})^{[14]}$ was carried out to create variables representing cyclic spatial relationships among 49 states of the US in decreasing order of spatial scale. Alaska and Hawaii were excluded from the analysis to maintain spatial connections between the statistical units. Since Alaska and Hawaii are located so far from other states and they have no actual adjacent states with a common border, Alaska and Hawaii would have seriously impaired completeness of the sampling area's (the US in this case) geographic coverage, the key attribute of the PCNM quality. First, a 2-dimensional matrix of Euclidean distances among the states was conducted using the latitudes and longitudes (World Geodetic System, WGS84 decimal degrees) of geographical centers of the largest settlement concentrations, cities or metropolitan areas, of the states as initial values. Second, a truncated connectivity matrix was constructed according to a specific rule with respect to a threshold value that indicates the wavelength of the smallest spatial scale in the context. ${ }^{[15]}$ Third, eigenvectors were extracted from the centered truncated connectivity matrix. PCNM searches for eigenvectors corresponding to autocorrelation and uses them to describe spatial structures in a given dataset. ${ }^{[14,15]} \mathrm{PCNM}$ results in variables corresponding to positive and negative eigenvectors but usually only the positive ones are taken into account in further analyses. Negative eigenvectors model negative spatial correlation and they also may be useful in some specific instances. The eigenvectors are rotated so that they do not correlate with each other and sample locations can be randomly or systematically assigned. PCNM variables can be considered as reflections of real predictors if 1) each predictor obeys one or more spatial patterns and 2) the geographic coverage of 
the sampling area is complete enough so that PCNM reflects most spatial patterns. In other words, PCNM variables can act as proxies for any kind of process resulting in spatial structuration of the response variable(s). For a more detailed description of the PCNM method and how it can be applied to spatial epidemiology see our previous work. ${ }^{[16]}$ The PCNM variables were created using functions of the spacemakeR package for the $\mathrm{R}$ statistical language. ${ }^{[15]}$

A linear regression with forward stepwise procedure was performed using mortality as a dependent variable and PCNM variables with a positive eigenvalue as independent variables. The number of independent variables in the final model was determined on the basis of the so-called double stopping criterion to avoid reporting an inflated explanatory power. ${ }^{[17,18]}$ Furthermore, the independent variables of the final model were used as explanatory variables in simple linear regressions to explain the proportions of different ethnic groups in the US population at the state-level. The regression analyses were performed with the IBM SPSS 19 for Windows.

The Durbin-Watson statistic ${ }^{[19-21]}$ was used to detect autocorrelation between mortality and the proportions of different ethnic groups in the US population at the state-level. In each case, two values of the Durbin-Watson test statistic (d) were calculated, from the dataset arranged according to latitudes and from the dataset arranged according to longitudes using functions of the lmtest package for the $\mathrm{R}$ statistical language. This enabled to compare the North-South dimension to East-West dimension as a source of autocorrelation. When combined to the PCNM results, the Durbin-Watson statistic helped to locate the areas in the US where brain cancer mortality is most strongly associated with certain ethnic groups.

The Mantel test ${ }^{[22]}$ was used to test the correlation between the matrices representing brain cancer mortality and proportions of different ethnic groups in the population at the state-level. As the matrices were arranged according to the geographical distances across the states based on latitudes and longitudes, the Mantel test results indicated correlative relationships between the spatial patterns of the brain cancer mortality and those obeyed by the distribution of different racial and ancestral groups. The Mantel tests were executed using functions of the ade 4 package for the $\mathrm{R}$ statistical language.

\section{RESUlts}

\subsection{Spatial patterns}

PCNM resulted in 26 variables with a positive eigenvalue. The first PCNM variable corresponded to the largest-scale variation in the study area with the cycle wavelength of sev- eral hundreds of kilometers. It contrasted two large areas so that states located in the Northeastern US had the most positive and those located in the Midwestern and South Central US the most negative site scores (see Figure 1). The other two most important PCNM variables with respect to the spatial patterns of brain cancer mortality and distribution of different ethnic groups appeared to be the sixth and ninth vectors. The sixth PCNM variable contrasted the Southwestern US from Northwestern US, whereas the ninth PCNM variable mainly contrasted Florida, Georgia, and Illinois from their neighbor states (see Figure 1). In other words, geographic variation in brain cancer mortality partly obeyed the same PCNM vectors, particularly 1, 6, and 9, as geographic variations in the relative abundance of different ethnic groups. The presence of covariation indicates a contingent causal relationship between the variables, mortality and ethnicity.
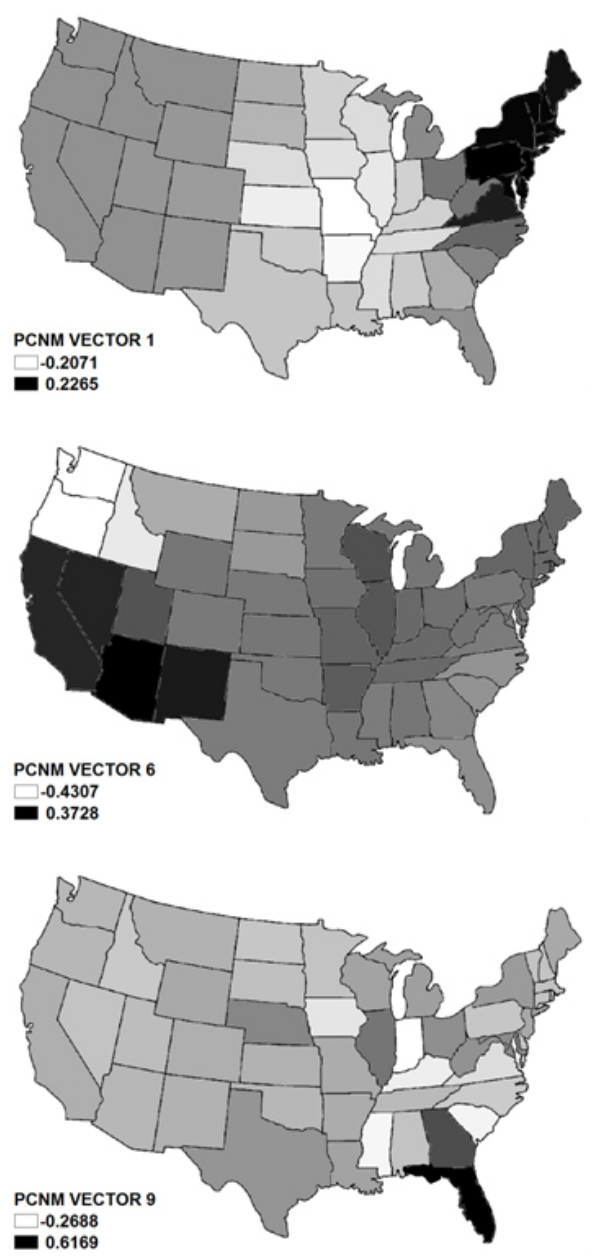

Figure 1. PCNM vectors were used to model the spatial patterns of brain cancer mortality as well as the proportions of different ethnic groups at the state-level. The vectors 1,6 , and 9 were the most important explanatory variables in the models 


\subsection{Overall brain cancer mortality}

The spatial analyses revealed that the geographic distribution of overall brain cancer mortality was related to the proportion of foreign-born Black and White populations (including Hispanic) so that the mortality was highest in the states were the proportion of foreign-born was low and vice versa (see Figure 2). According to the linear regression, the PCNM variables $1,6,13,3$, and 9 , presented in the order of relative significance, explained $43 \%$ of the variation in the overall brain cancer mortality at the state-level. The same PCNM variables explained 49 and $29 \%$ of the spatial distribution of foreign-born Black and White populations, respectively (see Table 1). In the case of foreign-born Black, the PCNM variable 1 was the most significant one, whereas in the case of foreign-born White, the PCNM variable 9 had the highest explanatory power (see Figures 1 and 2). This means that geographic variation in brain cancer mortality was associated both with variations in the relative abundance of foreign-born Black, via the PCNM variable 1, and foreign-born White, via the PCNM variable 9. The Durbin-Watson statistic emphasized the importance of the East-West dimension instead of North-South dimension and foreign-born White instead of foreign-born Black in creating autocorrelation between overall brain cancer mortality and distribution of foreignborn population in general (see Table 1). The Mantel test, for its part, highlighted the statistically significant correlative relationship between brain cancer mortality and proportion of American-born White (see Table 1). The proportion of American-born White in the state's population, however, also correlated with the proportion of foreign-born White (Pearson's $r=0.61, p<.0001$ ), which most probably acted as a confounding factor in the relationship between the brain cancer mortality and American-born White.

Table 1. State-level relationships between the overall brain cancer mortality and proportions of different ethnic groups in the population

\begin{tabular}{|c|c|c|c|c|c|c|c|c|c|}
\hline \multirow{2}{*}{ Group } & \multirow{2}{*}{$\begin{array}{l}\text { Mean } \\
(\%)\end{array}$} & \multicolumn{2}{|l|}{ PCNM } & \multicolumn{2}{|c|}{ DW (Latitude) } & \multicolumn{2}{|c|}{ DW (Longitude) } & \multicolumn{2}{|c|}{ Mantel test } \\
\hline & & adj. $r^{2}$ & $p$-value & $d$ & $p$-value & $d$ & $p$-value & $r$ & $p$-value \\
\hline White & 77.2 & 0.012 & .366 & 1.854 & .278 & 1.885 & .337 & 0.289 & $<.001$ \\
\hline Black & 11.5 & -0.074 & .885 & 1.890 & .326 & 1.944 & .392 & 0.151 & .027 \\
\hline Asian & 2.94 & 0.083 & .119 & 1.735 & .176 & 1.628 & .086 & 0.100 & .098 \\
\hline F-b & 8.65 & 0.242 & .004 & 1.940 & .417 & 1.458 & .024 & 0.249 & $<.001$ \\
\hline A-b White & 73.0 & 0.087 & .111 & 1.881 & .314 & 1.859 & .307 & 0.352 & $<.001$ \\
\hline A-b Black & 10.7 & -0.090 & .957 & 1.863 & .292 & 1.924 & .366 & 0.122 & .052 \\
\hline A-b Asian & 0.91 & 0.060 & .179 & 1.697 & .144 & 1.603 & .073 & 0.091 & .112 \\
\hline F-b White & 4.25 & 0.285 & .001 & 1.827 & .270 & 1.463 & .026 & 0.187 & .006 \\
\hline F-b Black & 0.81 & 0.491 & $<.001$ & 1.834 & .270 & 2.258 & .806 & 0.277 & .001 \\
\hline F-b Asian & 2.03 & 0.096 & .094 & 1.753 & .193 & 1.648 & .099 & 0.104 & .089 \\
\hline
\end{tabular}

Note. PCNM, Principal Coordinates of Neighbor Matrices; DW, Durbin-Watson; F-b, Foreign-born; A-b, American-born. Durbin-Watson p-value is for positive autocorrelation.

3.3 Brain cancer mortality among White Non-Hispanic Italian, Russian, Austrian, and German were the only ancestries which were associated with brain cancer mortality among White Non-Hispanics according to all three spatial analyses: PCNM, Durbin-Watson, and Mantel (see Table 2). In the case of Italians, Russians, and Austrians, lower mortality rates were associated with these ethnic groups while in Germans, mortality was increased. Here, Russian refers to the area of former Soviet Union excluding Estonia, Latvia, and Lithuania. In the linear regression, the PCNM variables $1,6,15,13$, and 21 , presented in the order of relative significance, explained $48 \%$ of the variation in brain cancer mortality among White Non-Hispanics at the state-level. The same PCNM variables explained 51\%, 31\%, 14\%, and 15\% of the distribution of Italian, Russian, Austrian, and German ancestries, respectively (see Table 2). Again, the DurbinWatson statistic highlighted the importance of the East-West dimension instead of North-South dimension in generating autocorrelation between the brain cancer mortality among White Non-Hispanic and distribution of different ancestral groups (see Table 2). From the viewpoint of the brain cancer mortality in general, Italian and German can be considered as the most important ancestries due to their high abundance in the US population as well as because of their opposite effects on the mortality (see Figure 3). The Mantel test also pointed out the Italian and German ancestries (see Table 2). Interestingly, the only ancestries which were associated with increased mortality among White Non-Hispanics in the US population were from a relatively restricted area in Europe including Germany, Czech Republic, the Netherlands, Luxemburg, Belgium, and the Nordic countries except for Iceland (see Figure 4). All other ancestries were associated with decreased mortality; Italian, Greek, Syrian, and Moroc- 
can showing the strongest effect per se (see Figure 4). The serious outliers in most plots.

District of Columbia and North Dakota had to be excluded

from the analyses of White Non-Hispanics, as they acted as
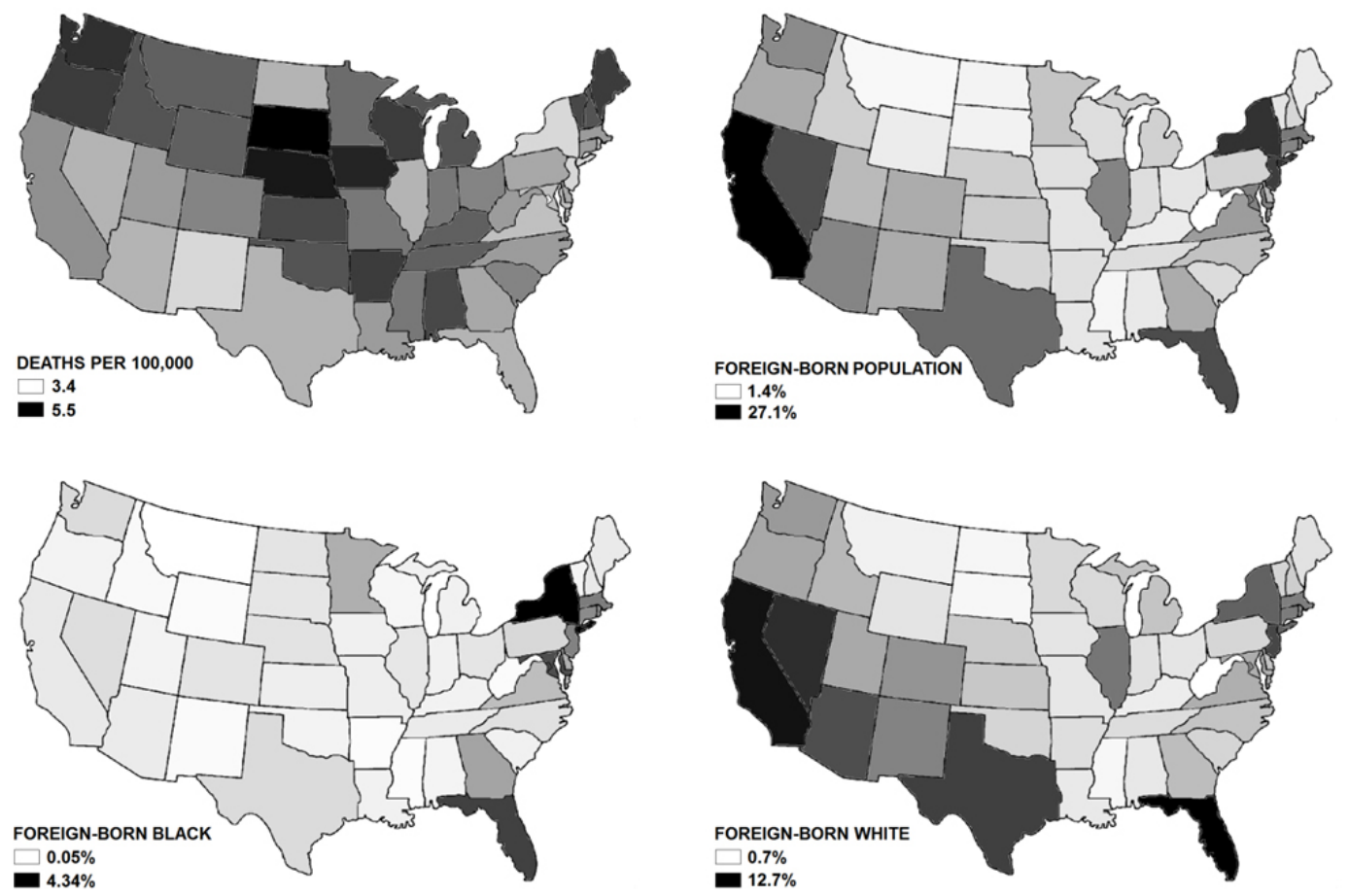

Figure 2. The state-level spatial distribution of overall brain cancer mortality (average annual rate 2007-2011) was explained by the proportion of foreign-born population (as in 2010), more precisely, by the proportions of foreign-born White and Black

Table 2. State-level relationships between the brain cancer mortality among White Non-Hispanic and proportions of different ancestral groups in the population

\begin{tabular}{|c|c|c|c|c|c|c|c|c|c|}
\hline \multirow{2}{*}{ Group } & \multirow{2}{*}{$\begin{array}{l}\text { Mean } \\
(\%)\end{array}$} & \multicolumn{2}{|l|}{ PCNM } & \multicolumn{2}{|c|}{ DW (Latitude) } & \multicolumn{2}{|c|}{ DW (Longitude) } & \multicolumn{2}{|c|}{ Mantel test } \\
\hline & & adj. $r^{2}$ & $p$-value & $d$ & $p$-value & $d$ & $p$-value & $r$ & $p$-value \\
\hline Italian & 5.85 & 0.508 & $<.001$ & 1.882 & .337 & 1.096 & $<.001$ & 0.239 & .008 \\
\hline Greek & 0.45 & 0.450 & $<.001$ & 1.833 & .277 & 1.492 & .032 & 0.131 & .059 \\
\hline Hungarian & 0.35 & 0.162 & .030 & 1.952 & .428 & 2.080 & .590 & 0.102 & .118 \\
\hline Irish & 10.9 & 0.465 & $<.001$ & 2.234 & .787 & 1.186 & .001 & 0.088 & .148 \\
\hline Austrian & 0.18 & 0.144 & .042 & 1.604 & .082 & 1.435 & .020 & 0.147 & .021 \\
\hline Polish & 2.68 & 0.132 & .054 & 1.477 & .032 & 1.840 & .271 & 0.069 & .178 \\
\hline Slovak & 0.16 & 0.053 & .205 & 1.913 & .377 & 2.141 & .669 & 0.055 & .236 \\
\hline Russian* & 1.14 & 0.312 & .001 & 1.774 & .213 & 1.132 & .001 & 0.161 & .035 \\
\hline Portuguese & 0.57 & 0.086 & .122 & 1.879 & .332 & 1.561 & .055 & 0.210 & .046 \\
\hline Norwegian & 2.24 & 0.036 & .266 & 1.634 & .099 & 1.885 & .326 & 0.162 & .057 \\
\hline German & 17.2 & 0.153 & .036 & 2.240 & .793 & 1.338 & .008 & 0.185 & .012 \\
\hline Czech & 0.49 & 0.116 & .072 & 1.936 & .407 & 1.423 & .018 & 0.199 & .051 \\
\hline Dutch & 1.28 & 0.094 & .106 & 2.466 & .947 & 1.734 & .163 & 0.173 & .049 \\
\hline
\end{tabular}

Abbreviations: PCNM, Principal Coordinates of Neighbor Matrices; DW, Durbin-Watson.

*Refers to the area of the former Soviet Union excluding Estonia, Latvia, and Lithuania.

The smallest groups $(<0.1 \%)$ as well as those having only a very weak correlative relationship with the brain cancer mortality were omitted from the table for the sake of clarity. District of Columbia (highest mortality among White Non-Hispanic) and North Dakota (lowest mortality) were excluded from the analyses as they acted as outliers in most plots. Durbin-Watson $p$-value is for positive autocorrelation. 

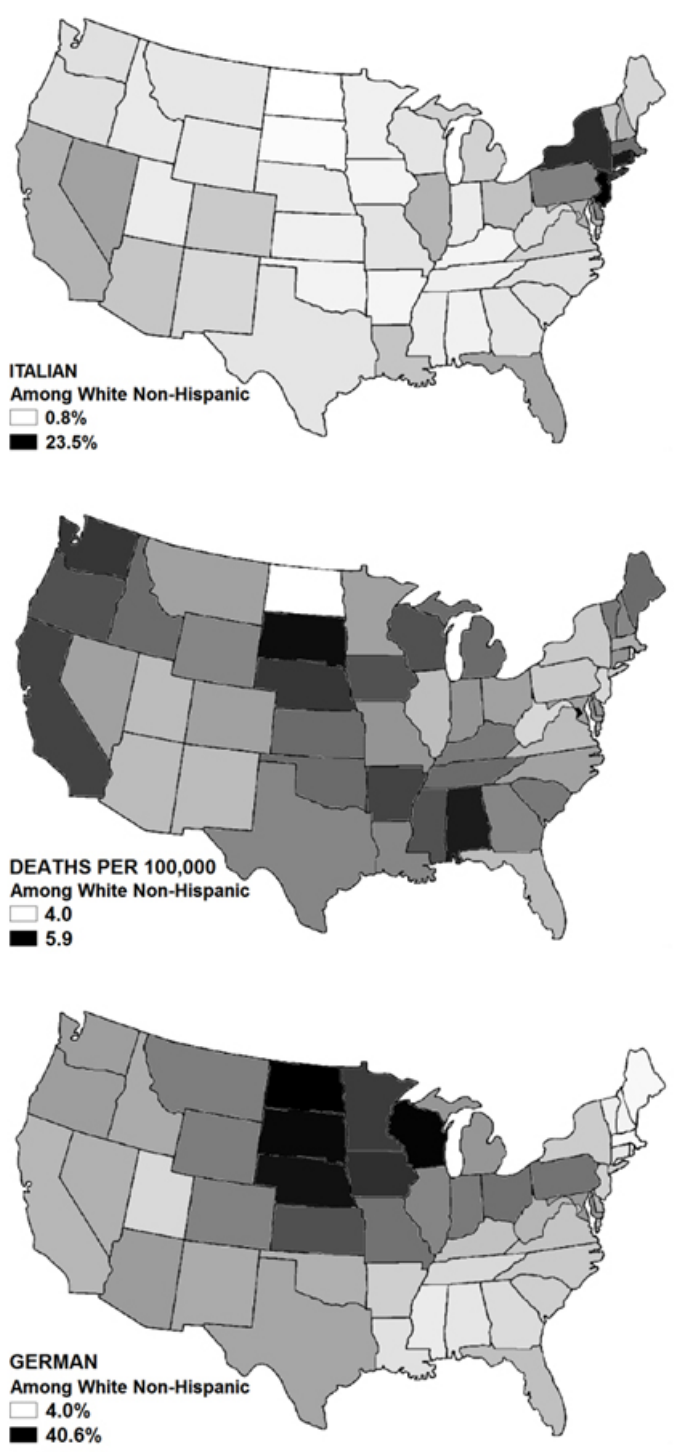

Figure 3. The state-level spatial distribution of brain cancer mortality among White Non-Hispanic (average annual rate 2007-2011) was explained by the proportions of different ancestral groups (as in 2010), Italian and German being the most significant ones

\section{Discussion}

The main questions concerning the interpretation of the present results are: how well the ancestry and ethnic origin represents possible genetic differences across groups or are they just indicators of cultural issues? Although some potential environmental determinants of brain cancer have been recognized, the truth is that current explanations for brain cancer are increasingly being sought in the genome. ${ }^{[8,10]}$ Consequently, it is not expectable to find cultural factors which would explain the differences in brain cancer mortality between ancestral and ethnic groups. This study emphasized the role played by certain European ancestries in the US

Published by Sciedu Press brain cancer mortality, as the only ancestries associated with increased mortality were from a relatively restricted area comprised of nine neighboring countries located in the Central and Northern Europe. Of these nine countries especially Sweden and Norway are characterized by the highest brain cancer incidence rates in the world. ${ }^{[1]}$ The genetic structure of the European population corresponds to the geographic structure rather well, ${ }^{[23]}$ which, in turn, gives reasons for the discussion about the possible existence of population-level genetic susceptibilities to the brain cancer and/or higher risk of mortality.

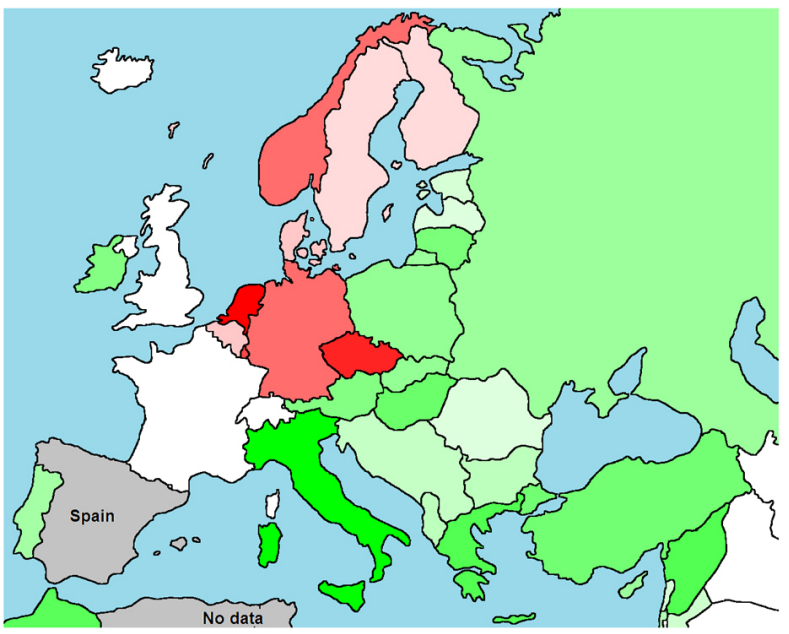

Figure 4. The main ancestral groups of the US White Non-Hispanic population. Colors indicate the power $\left(r^{2}\right)$ of the groups in explaining the brain cancer mortality among the US White Non-Hispanic population: the brighter the color the higher the power. Red colors mean that the group in question increases the mortality and green colors that the group decreases the mortality. White color means no correlative relationship between the mortality and ancestral group. Spanish are classified as Hispanic and, consequently, Spain was excluded from the analysis

On the other hand, there appeared to be a link between the brain cancer mortality and birthplace, as the foreign-born population had lower regional mortality rates. This may be interpreted that people born outside the US have a lower mortality risk, but living in the US increases the risk and the American-born children of the foreign-born parents do not benefit from their parents' origin. Unfortunately, it is very difficult to verify or reject the interpretation, since the reliability of brain cancer data varies widely across countries being low, especially, in many "key areas", such as Africa and the Middle East. ${ }^{[1,2]}$ What explains the observed difference in brain cancer mortality between the American- and foreignborn people? Toxoplasma gondii, a parasite associated with the increased risk of brain cancer, ${ }^{[24]}$ does not, as $T$. gondii 
is much more common among the foreign- than Americanborn, ${ }^{[25]}$ not vice versa which would have supported the present finding. An exposure to the radiofrequency electromagnetic fields from mobile phones and mobile-phone base stations, in turn, is a very ambiguous explanatory factor due to the lack of clear consensus regarding the association between brain cancer and mobile phones in general; "limited evidence" of an increased risk of brain tumors in long-term mobile phone users have been suggested. ${ }^{[26-28]}$ However, the reported correlative state-level relationship between the brain tumor incidence and number of cell phone contracts in the US, ${ }^{[29]}$ stresses the need for more epidemiologic research.

If the reason for the higher brain cancer mortality rate among American-born would be the increased long-term exposure to electromagnetic radiation as a result of using a mobile phone ${ }^{[30]}$ it also would explain the North Dakota "anomaly" in the present study. The brain cancer mortality rates in North Dakota among White Non-Hispanics was much lower than expected on the basis of peoples' ancestries, but at the same time the number of cell phone subscriptions also was lowest in North Dakota among the states studied. ${ }^{[29]}$ According to the same inference, the District of Columbia "anomaly", a higher mortality rate among White Non-Hispanic than expected, would be explained if people living in the District of Columbia would be exposed to large amounts of electro- magnetic radiation from mobile phones, mobile-phone base stations, or some other sources. The number of cell phones per capita is highest in the District of Columbia among all states. $^{[31]}$

\section{Limitations}

The observed associations between brain cancer mortality and population ancestries are spatial associations based on state-level data; they do not reveal actual relationships at the individual-level. Although group-level associations arise from individual-level actions and qualities, and they can be supported by individual-level associations, conclusions drawn from the group-level associations cannot be returned to individuals, it leads to ecological fallacy. Moreover, as the present data do not include the strength of radiofrequency electromagnetic fields and exposure duration, no strong conclusions regarding the relationship between brain cancer death rates and exposure to electromagnetic fields from mobile phones at the state-level can be drawn.

\section{Conclusions}

The present findings gave reasons for the discussion concerning the possible existence of population-level genetic susceptibilities to the brain cancer and/or higher risk of mortality.

\section{REFERENCES}

[1] Cancer Research UK. Worldwide cancer mortality statistics [Internet]. Retrieved October 31, 2014. Available from: http://ww w. cancerresearchuk orghealth-professional/cancer-s tatistics/worldwidecancer/mortality\#heading-Zero

[2] World Health Organization. International Agency for Research on Cancer [Internet]. Retrieved October 31, 2014. Available from: http://www.iarc.fr

[3] Siegel R, Ma J, Zou Z, et al. Cancer statistics. CA Cancer J Clin. 2014; 64(1): 9-29. http://dx.doi.org/10.3322/caac. 21208

[4] State Cancer Profiles. Data topics: mortality [Internet]. Retrieved October 31, 2014. Available from: http://statecancerprofile s.cancer.gov/data-topics/mortality.html

[5] Johnson DR, O'Neill BP. Glioblastoma survival in the United States before and during the temozolomide era. J Neurooncol. 2012; 107(2): 359-364. PMid:22045118. http://dx.doi.org/10.1007/s1106 0-011-0749-4

[6] Ohgaki H, Kleihues P. Epidemiology and etiology of gliomas. Acta Neuropathol. 2005; 109(1): 93-108. PMid:15685439 http: //dx.doi.org/10.1007/s00401-005-0991-y

[7] Braganza MZ, Kitahara CM, de González AB, et al. Ionizing radiation and the risk of brain and central nervous system tumors: a systematic review. Neuro Oncol. 2012; 14(11): 1316-1324. PMid:22952197. http://dx.doi.org/10.1093/neuonc/nos208

[8] Kitahara CM, Linet MS, Brenner AV, et al. Personal history of diabetes, genetic susceptibility to diabetes, and risk of brain glioma: a

pooled analysis of observational studies. Cancer Epidemiol Biomarkers Prev. 2014; 23(1): 47-54. PMid:24220915. http://dx.doi.o $\mathrm{rg} / 10.1158 / 1055-9965$.EPI-13-0913

[9] Cahoon EK, Inskip PD, Gridley G, et al. Immune-related conditions and subsequent risk of brain cancer in a cohort of 4.5 million male US veterans. Br J Cancer. 2014; 110(7): 1825-1833. PMid:24595001. http://dx.doi.org/10.1038/bjc. 2014.97

[10] Egan KM, Baskin R, Nabors LB, et al. Brain tumor risk according to germ-line variation in the MLLT10 locus. Eur J Hum Genet. 2015; 23(1): 132-134. PMid:24755950. http://dx. doi.org/10.1038 /ejhg. 2014.70

[11] Ostfeld RS, Glass GE, Keesing F. Spatial epidemiology: an emerging (or re-emerging) discipline. Trends Ecol Evol. 2005; 20(6): 328-336. PMid:16701389. http://dx.doi.org/10.1016/j.tre e.2005.03.009

[12] Bivans RS, Pebesma E, Gómez-Rubio V. Applied Spatial Data Analysis with R. New York, NY: Springer; 2013.

[13] United States Census Bureau. American FactFinder [Internet]. Retrieved October 14, 2014. Available from: http://factfinder2. census.gov/faces/nav/jsf/pages/index.xhtml

[14] Borcard D, Legendre P. All-scale spatial analysis of ecological data by means of principal coordinates of neighbour matrices. Ecol Model. 2002; 153(1-2): 51-68. http://dx.doi.org/10.1016/S0304-3 800 (01) 00501-4

[15] Dray S, Legendre P, Peres-Neto PR. Spatial modeling: a comprehensive framework for principal coordinate analysis of neigh- 
bour matrices (PCNM). Ecol Model. 2006; 196(3-4): 483-493. http://dx.doi.org/10.1016/j.ecolmodel.2006.02.015

[16] Voutilainen A, Tolppanen A-M, Vehviläinen-Julkunen K, et al. From spatial ecology to spatial epidemiology: modeling spatial distributions of different cancer types with principal coordinates of neighbor matrices. Emerg Themes Epidemiol. 2014; 11: 11. http://dx.doi.org/10.1186/1742-7622-11-11

[17] Blanchet FG, Legendre P, Borcard D. Forward selection of explanatory variables. Ecology. 2008; 89(9): 2623-2632. PMid:18831183. http://dx.doi.org/10.1890/07-0986.1

[18] Gilbert B, Bennett JR. Partitioning variation in ecological communities: do the numbers add up? J Appl Ecol. 2010; 47(5): 1071-1082. http://dx.doi.org/10.1111/j.1365-2664.2010.01861.x

[19] Durbin J, Watson GS. Testing for serial correlation in least squares regression, I. Biometrika. 1950; 37(3/4): 409-428. http://dx. doi . org $/ 10.2307 / 2332391$

[20] Durbin J, Watson GS. Testing for serial correlation in least squares regression, II. Biometrika. 1951; 38(1/2): 159-179. http://dx.d oi.org/10.2307/2332325

[21] Durbin J, Watson GS. Testing for serial correlation in least squares regression, III. Biometrika. 1971; 58(1): 1-19. http://dx. doi.o $\mathrm{rg} / 10.2307 / 2334313$

[22] Mantel N. The detection of disease clustering and a generalized regression approach. Cancer Res. 1967; 27(2): 209-220. PMid:6018555.

[23] Lao O, Lu TT, Nothnagel M, et al. Correlation between genetic and geographic structure in Europe. Curr Biol. 2008; 18(16): 12411248. PMid:18691889. http://dx.doi.org/10.1016/j.cub.2 008.07 .049

[24] Vittecoq M, Elguero E, Lafferty KD, et al. Brain cancer mortality rates increase with Toxoplasma gondii seroprevalence in France.
Infect Genet Evol. 2012; 12(2): 496-498. PMid:22285308. http: //dx.doi.org/10.1016/j.meegid.2012.01.013

[25] Jones JL, Kruszon-Moran D, Wilson M. Toxoplasma gondii infection in the United States, 1999-2000. Emerg Infect Dis. 2003; 9(11): 1371-1374. PMid:14718078. http://dx.doi.org/10.3201/eid 1304.061355

[26] Hardell L, Carlberg M, Söderqvist F, et al. Meta-analysis of longterm mobile phone use and the association with brain tumours. Int $\mathrm{J}$ Oncol. 2008; 32(5): 1097-1103. PMid:18425337. http://dx.doi .org/10.3892/ijo.32.5.1097

[27] Baan R, Grosse Y, Lauby-Secretan B, et al. Carcinogenicity of radiofrequency electromagnetic fields. Lancet Oncol. 2011; 12(7): 624-626. PMid:21845765. http://dx.doi.org/10.1016/S1470 -2045 (11) 70147-4

[28] Cardis E, Armstrong BK, Bowman JD, et al. Risk of brain tumours in relation to estimated RF dose from mobile phones: results from five Interphone countries. Occup Environ Med. 2011; 68(9): 631640. PMid:21659469. http://dx.doi.org/10.1136/oemed-2 011-100155

[29] Lehrer S, Green S, Stock RG. Association between number of cell phone contracts and brain tumor incidence in nineteen U.S. States. J Neurooncol. 2011; 101(3): 505-507. PMid:20589524. http://dx.doi.org/10.1007/s11060-010-0280-z

[30] Baron NS, Hård af Segerstad Y. Cross-cultural patterns in mobilephone use: public space and reachability in Sweden, the USA and Japan. New Media Soc. 2010; 12(1): 13-34. http://dx. doi .org $/ 10.1177 / 1461444809355111$

[31] Federal Communications Commission. Statistical trends in telephony [Internet]. Retrieved November 17, 2014. Available from: http://transition.fcc.gov/wcb/iatd/trends.html 